\title{
Engage Them, Don't Enrage Them - Student Voices and What It Takes to Participate
}

\author{
Dr Rima Aboudan (Corresponding author) \\ Department of Linguistics, Faculty of Humanities and Social Sciences \\ P O Box 17771, United Arab Emirates University \\ United Arab Emirates
}

Tel: 971-3-768-2297Ｅ-mail: Raboudan@uaeu.ac.ae

\begin{abstract}
Students who get involved reap several academic benefits (Furtwengler: 1991). This paper concerns features of pedagogy that involve students, get them to participate, and capture and sustain their interest. Analysis of data from feedback by 80 students and 40 faculty members in the United Arab Emirates University highlighted four core components in motivating student participation: the content connect-ability of subject-matter to students' everyday lives; the use of student active-involvement opportunities in lessons; the students' sharing of responsibility in the learning process; and the establishment of a rewarding system for effort and engagement.
\end{abstract}

Keywords: Education, Motivation, Participation, Student Voices

\section{Background}

Two out of three students are bored in college classes every day; and $17 \%$ are bored in every class (Yazzie-Mintz, 2007). An increasing focus on boredom during class time is, in part, due to the fact that boredom has been linked to a number of educational problems such as resistance to school (Larson and Richards, 1991), higher rates of dropping out of school (Farrell, Peguero, Lindsey, \& White, 1988), and student educational and psychological disengagement from the learning situation (Eccles et al., 1993).

Existing research suggests that classroom boredom materializes as a result of three possible factors: (a) students dislike the material and therefore are unable to achieve class stimulation (Iso-Ahola \& Weissinger, 1987), (b) they find the material "uninteresting" or "irrelevant" to their study interest (Csikszentmihalyi, 1990), and (c) if they experience inadequate teacher interaction (Iso-Ahola \& Weissinger, 1987; Weissinger, Caldwell, \& Bandalos, 1992). If those feelings transpire, students disengage educationally, and mirror this disengagement through the experience of boredom (Eccles et al., 1993). Undoubtedly, such feelings of disengagement are educationally non-productive, so much so that boredom may become a new challenge to college students as they take on greater study responsibilities (Farrell, Peguero, Lindsey, \& White, 1988). An apparent consensus in existing research is that once boredom is perceived, students start to lack the ability to get stimulated and are less likely to participate (Caldwell, Darling, Payne, \& Dowdy, 1999). This line of discussion in the literature suggests that frequent occurrence of boredom makes the feeling of being bored a standard means of communication that turns into a routine aspect of the adolescent classroom situations (Larson and Richards, 1991).

\section{Are Emirati students apathetic, unmotivated, uninvolved and bored?}

Oddly, students are mostly outside the learning loop and the process of its improvement. This peculiar circumstance has been highlighted previously. For the most part, "The only group whose voice seems strangely absent in this chorus of ideas and counter ideas [in learning] is that of the students themselves" (Johnson: 1991)

In more recent years, the 'student voice movement' started to focus on finding out what students think about their experience of being learners, what gets in the way of their learning, and what helps them to learn (Rudduck \& Flutter, 2004: p. 2). Conducting investigations of students' views, and including a 'stakeholder' perspective to what they have to say has been markedly a strong demeanor in many educational institutions around the world (Wood, 2003). A commendable work in this regard has been done in Europe by European National Students Union and the national Unions of Students of Europe. Similar exemplary work on the effectiveness of student engagement in improving institutions' quality of practice was done in the USA, Scotland and South Africa.

Taking cue from such noteworthy efforts and as the central role of student in education is, in principle, agreed on by the policy and decision makers at U.A.E.U, the experience of actual involvement of students, picked up pace at the United Arab Emirates University in recent years. 


\section{Research focus}

Debate among college instructors at the United Arab Emirates University (U.A.E.U) about how can educators capture and sustain students' commitment to learning is very contemporary. Taking up the cause of advancing student involvement and participation in learning at U.A.E.U, I got interested in what instructors AND students have to say about the issue. To facilitate the initiative in this direction, I took part in the delivery of a college workshop organized by the University's Committee on Effective Teaching (CET) on student motivation and participation. So compelling were the points raised by both students and teachers that obligate sharing them with colleagues in educational programs both at U.A.E.U and other institutions.

From this perspective, this paper evolves on the main concern of finding the key pedagogical features that capture Emirati students' commitment to learning and sustain their participation in it.

The research focus aims at fulfilling the following key objectives:

A. collect, analyze and disseminate good practices in engaging students in better experiences of student participation

B. promote interdisciplinary exchange of good practices in student participation between different faculties at UAEU

\section{Research approach}

Recently, educational policies at U.A.E.U have shown significant interest in what students and faculty have to say about teaching, matters of curriculum revision, and discussions of pedagogy. Following a college of humanities generic survey on faculty development and student needs, and based on the survey results, faculty members and students were invited to participate in a major open-dialogue workshop on student motivation and participation. During the workshop, there was a great provision to take account of students' experiences and views about the way they are taught. During the workshop, students' presence and voices were expressed without any reluctance and constituted an important part of the discussion.

Subsequently to this workshop, investigation of teachers' and students' views on motivation and class participation continued in the form of informal discussions with educators and interviews with students. Results of those discussions and interviews showed, similarly to previous findings by Merriman (2004), that the general population of U.A.E.U educators, regardless of their institutional affiliation, do not yet have a sufficient understanding of what "motivates" students or what makes them take an interest in their learning, and more importantly, what causes them to be bored with the whole learning activity.

In a response to this state of ambivalence, and in order to find out what causes Emirati students to be bored and what engages them, (40) faculty members and (80) students were randomly selected as a 'core sample' to case-study the issue. The core sample included faculty and student participants from courses where the nature of the learning actively involves both parties (instructors and students) throughout the course period, and in which instructors were not constrained to rely on textbooks solely or on strict conventional pedagogical structures in their delivery. Faculty participants ranged in their academic positions from assistant to full professors. Students were in various years of study, including new enrolments, freshmen, students in subsequent years of study, and graduating students. Care was taken, moreover, to include both higher- and lower-achieving students.

A questionnaire-based approach was used with faculty. Students, on the other hand, were (1) asked to respond to a student questionnaire, (2) interviewed in groups of twos, and (3) encouraged to give their views and experiences and reflect freely on what educationally engages them in a web-based discussion log book that was established for that purpose.

Both faculty and student questionnaires had a core set of questions on student involvement and participation; and assurances of anonymity were given to everyone involved.

\section{Findings}

Views presented by students and faculty instructors in this Emirati case study have a wide implication on theories relating to student engagement and pedagogic structure. In general terms, and from a faculty perspective, many instructors suggested loosening the time-disciplined activities dictated by the daily rhythms of timetables and highly structured classroom environments. Faculty recommended that the relaxing of routine not only tackles the rigidity of having to be in a learning atmosphere for long daily hours, but also provides a different learning style especially for students who do not learn well in the traditional frame of classrooms. Holloway and Valentine (2003) and Rudduck \& Flutter (2004) had previously favored this concept of learning away from rigid classroom environments and highlighted its potential positive effect on offering opportunities for active learning. 
Transforming rigid learning environments to learning conducive settings has to start with letting students have their say and getting their voices heard. The students at U.A.E.U rose to the challenge, spoke eloquently of the sense of investment and trust, and gave insights on a range of issues that, to some faculty, may exert largely unnoticed effects on how students learn and thrive.

To do justice to the sharpness of those insights and the common sense and constructive suggestions students made, a verbatim account of some of their most powerful remarks on participation is warranted:

- "use ideas that deal with my personal experience, and let me present my life experiences and my views on real life issues"

- "use positive feedback. We know we are only students; we know we make mistakes; let our professors be positive in their corrections for us. They were students before and they used to make mistakes like us"

- "give us marks for our participation"

- "activities in which we learn with and from our friends in class are the most exciting"

- "group games make me participate more"

- "class discussions are very exciting and make students speak more in class"

- "always ask for our opinions. Sometimes I want to say something, but my teacher never asks if we want to say something"

- "if we have more questions and more projects in our learning then we will be more interested - instead of memorizing facts all the time"

Also, given the seriousness of the practical issues raised by the faculty, an outline of points made must be recalled:

- "I teach archaeology of the United Arab Emirates as part of a core course. On the first day of class, I asked my students: why did you register in this course? Almost everyone answered: "because we want to learn something about things in our lives and about things we can see and feel their importance". This was amazing. From day one, this response set the stage for my teaching."

- "show students how much you value their opinion and ideas - once students realize their voices are heard, they usually become more committed and interested"

- "make participation part of your summative evaluation; use a 'bonus mark' system; and don't forget to praise those who participate"

- "give them [students] a sense of your proximity to them - eye contact, positive attention, and postures of interest"

- "always create a harmonious 'easy-going' climate in your class"

- "foster a feeling in each student that $\mathrm{s} / \mathrm{he}$ is an important member of the group with something of worth to share"

- "give students a chance to voice their ideas"

- "personalize topics and provide live examples related to their [students'] environment"

- "It is not enough to reward students for achievement [thought competitions and giving students a sense of what they are good at and what they're not is good]. We have to reward participation and who works and who doesn't."

Some faculty remarks were stricter than others:

"show them what they stand to lose should they continue to display de-motivation"

"reduce their marks if they refuse to be involved as responsible learners"

"If they don't do their part, I don't do mine - they don't take part, I don't deliver mine - I would rather cancel the class and include the topic in exam"

Whether strict or more lenient, both students and faculty, as said in their own words, were in praise of participation.

\subsection{What captures and sustains students' interest and participation in learning at U.A.E.U?}

In particular, four factors that can support engagement and sustained student participation were highlighted by the present data:

- content connectedness to students' lives

- opportunities for students' active involvement 
- students' sharing of the responsibility in the learning process

5.1.1 Content connectedness to students' lives

There was considerable agreement between faculty instructors and students on the potential benefits of learning through the use of practical issues that relate to students' real experiences and realms of knowledge that have roots in the reality they live. A student studying Pedagogical Structure as part fulfillment of her course in linguistics said:

"I was never bored in acting out scenarios of real teaching. This is what we should do as students. The professor of this course gave us opportunities to feel what we read in the text book. This helped us learn about different ways of teaching and how students might behave in class. It was very easy to learn and also to remember what we learned when exam time came"

Students' appreciation of the connectedness of everyday life-based participatory activities to what they have to learn was emotionally expressed in one interview with a high-achieving student, as she explained her feedback on a multi-stage multi-cultural interview assignment required for in a Language and Culture course:

"I am so sad ... I am so sad [student getting tears in her eyes] that I did not do assignments like this [the interview assignment] before. This is my third year here (at U.A.E.U) and this is the first time I try something like this [the assignment]. I so enjoyed it and I learnt so much about other cultures. I mean it makes sense - if we speak with people from other cultures we learn about their language and their culture. I don't understand why we did not have something like that before"

The success of teaching using life knowledge is central to the theories of Kenway and Bullen's (2001) who point out that the indifference some students have towards learning and participation could be a resulting factor to not being realistically involved in whatever it is those students are doing in their classrooms.

One of the higher-achieving students shared her view about this:

"I became involved with my Language and Culture course right from the first class because my professor gave the group a culturally local case to handle. I easily connected and felt strongly that this would be an effective way for me to learn"

Equally important were the remarks made by faculty on connectedness of real life experiences to student learning. Students' interest, according to one faculty, "comes alive when they can relate knowledge taken from classrooms to the world they live in".

Another faculty suggested to:

"punctuate teaching with frequent real life examples or stories, because, this way, the students become internally more active in the class and they get involved without necessarily having to respond out loud."

Connectedness was also raised in relation to giving students a sense of enjoyment in their learning by some faculty:

"relating school learning to real people, things, social situations, families, local history and geography, intrigues students and excites them to investigate. Engaging students with content whilst giving them knowledge that they themselves are interested in creates 'happy knowledge' and when they feel happy, they enjoy. When they enjoy, they engage. When they engage, they learn"

\subsubsection{Opportunities for students' active involvement}

A student wrote in the web-based anonymous log book:

"I don't just want to have the book of the course - if we are there just to read from it, we can read it in our free time. I want to feel what the book says. Reading the paragraphs in class with teachers is just reading - no feeling in it"

A noteworthy point in one student's interview feedback was a useful distinction between being 'competitive' and 'cooperative'. Clearly the second was favored:

"it is good to know how good I am when I am compared to my friends in class. I feel happy if I compete with them sometimes; but I also really enjoy "sharing knowledge" with them - I learn from them and they learn from me - it is more easy and more fun. Some work on my own is ok. But more and more work with my friends is better. I help them, they help me - like that"

Another student fully agreed, stating that group work reduces boredom in class:

"I get bored when we don't do group work in class. My friends and I like to share what we learn. It makes us learn more because we do it [learning] together" 
A unique feature in faculty responses, on the other hand, was the strong reference to the power of collaborative work. A discussion of the effectiveness of collaboration was related to how naturally 'good' collaborative work can be. 'Good collaboration' was described by a faculty member as

"learning that does not divert away from achieving the objective of the class. The possibility of moving away from class objectives is a danger that we ought to be careful about".

The following comment from another faculty indicates agreement:

"In group collaboration, the best strategy is not just to get students to work together, but to have active exploration of concepts at hand and to follow course objectives."

The notion that group work helps create more active student engagement and participation was taken into another level of faculty support that one of the instructors wrote:

"group work often encourages weak students, who hardly ever participate for fear of being exposed, to get enthusiastic and to get into the flow of the learning stream"

Within the group of the 40 faculty members case studied, however, the extent to which group work could be manipulated provoked some disagreement:

Faculty A: "too much group work would turn our classrooms into a performance stage. How can we cover the required curriculum?"

Faculty B: "group work makes our classes more interesting, not only to students, but for us too"

FacultyC: "our commitment to course requirements does not support teaching models that favour classroom group-work opportunities"

The controversy over the issue of group work as a form of students' active involvement and participation surprised one faculty:

"the debate over the issue of group work surprises me. There is no right or wrong answer for this question [group work and its relation to active participation]. If your students work well with each other and do the job [learning], then your group work is rightly justified; if they don't, then not even the best participants in your class would benefit from it. Find what works in the frame of your classroom and structure your environment accordingly"

5.1.3 Students' responsibility in the learning process

Curriculum demands on both students and faculty are, more often than not, plentiful whatever educational institution one belongs to. Since we know that students are capable workers and willing to serve as partners (Kushman, 1997), sharing potential responsibilities outlined in course guidelines and objectives with students can lessen anxieties of hefty course strain on faculty, and give students opportunities to be more responsible learners and more involved in their own learning. Students in this case study reported their views on such possible responsibility:

An averagely-achieving student said in her interview:

"at start, it was scary that I have to decide on the topic of my second course project I have to do for my Language and Culture course. I never chose a project topic for myself before; usually the professor gives the projects. But, when my professor said she will direct me and supervise me, I got the courage and chose my topic and checked that with my professor and she said it was good. I am so happy, I chose my project topic"

Another student expressed how she felt in very simple but profound words:

"In one of my classes I enjoyed the way that Miss started. She asked us to tell her what we want to do during class, what we want to learn, how do we like to learn. So we have a choice, we can have opinions, we can agree and not agree, oh - disagree. I was not bored in that class"

Simple as this student's reaction is, it rings true with what MacBeath et al. (2003: p.1) argued for:

"Consulting young people ... can encourage them to feel that they belong, and that they are being treated in an adult way"

A lower-achieving student felt cared about when given the opportunity to share teaching part of a lesson to the rest of the class:

"I like my professor much better now - he trusted my ability to lead a class. That's why I prepared so much for this [sharing the teaching of the class]"

Opportunities of shadow classroom teaching were in fact popular to most students:

Student A: "I feel treated as responsible person - just like being a real teacher" 
Student B: "my teacher must respect me and my skills to ask me to share teaching the class with her"

Some students even enjoyed the 'power' associated with being a shadow teacher:

"I feel important and respected, just like a teacher; and I can force my classmates to pay attention"

Issues of students' responsibility also arose in the feedback by faculty, who, in general, agreed that students usually want to be given some learning responsibility and to feel that they are being noticed. One faculty pointed out that handing some responsibility to students creates "a more positive feeling about the subject and a better teacher-student relationship". Another faculty felt proud as he succeeded to alter the attitude of his lower achieving students, in particular those who have accumulated negative attention because of their poor performance, to feeling that they were treated as reliable individuals:

"my weak students now value being treated as important members of the team in my class. They don't feel deprived of attention no more. This is all because throughout my classes, I gave them some lay way to share their work with their fellow students, and handed them some responsibility as shadow teacher assistants. I am so proud of them, and I made sure they know that"

"students stay interested and learn more from the class when we [the instructors] use techniques to involve them in the learning process: we can tell a story about the material or give them collaborative learning projects"

\subsection{Rewarding engagement, increasing participation}

Given the seriousness and undoubted effect of engaging students and sustaining their participation on successful learning, the idea of 'rewarding' them when they do participate becomes reasonably justifiable and rather encourageable. This includes giving students extra marks, or even subject-related artifacts that could capture their interest and show appreciation of their efforts.

"although I teach graduating students, their learning interest quickened and their enthusiasm heightened when I gave them personalized pens a week before their quizzes. A small token went a long way. They all reviewed for quiz; I felt they wanted to thank me this way"

The faculty who wrote this comment in his feedback favoured rewarding students for their efforts - an approach he described as "infinitely and fascinatingly engaging, and intrinsically meaningful".

In her own words, one not highly-achieving student rather proudly said during her interview:

"I usually don't speak in class, but this one teacher makes me feel ok to ask questions because she reacts nicely to me when I ask - and she says "excellent question". Also, I think she finds my questions important because sometimes she asks other students to try to answer my questions"

A student with low to medium results in her average performance wrote a comment that, as educators, we should take quite seriously:

"I hate [student mentioned one of her courses]. My teacher only says 'yes', 'no' to my answers. I feel he is very negative with me. He should show me why my answer is wrong, and when it is correct, he should tell me that I am good"

On the whole, U.A.E.U students less than often make decisions or express their views about teaching and learning. As their voices are not commonly heard, it is recommended to cease opportunities of their readiness to talk and reward their willingness to share. Developing this way of working with students could help create a flexible zone where both students and teachers learn from their participation.

\section{Conclusion}

A number of educational institutions around the world have had their own success stories in engaging students to learn about issues concerning participation and motivation. Taking note of the worldwide initiatives, there is now a widespread commitment to engage students in discussions of teaching and learning at U.A.E.U. This study aimed at hearing and making Emirati student voices heard. Examining students' and faculty's voices lead to establish an understanding of what motivates student participation and involvement, irrespective of subject taught and topic under discussion. It is now clear that there are, in particular, four core components that could motivate Emirati students to engage and participate: including content (examples/ illustrations) that connects with Emiratis' everyday lives; offering opportunities for Emirati students to be actively involved in lessons; rewarding student involvement efforts and engagement; and giving students greater responsibility in planning and executing the learning process.

Of course, teaching is not an easy profession; and some do find it hard to be teachers. Once a teacher, listen to your students and let them speak their minds; be sensitive to what students say; and take notice of what they positively respond to. 
This study lays special emphasis on recommending more sensitivity to student voices in shaping up efforts to improve student involvement and participation, and concludes that getting students involved can prevent learning from becoming a boring 'course' shuffle without substance. It is a starting hope for UAEU that the Emirati system of higher education is so totally ready to appreciate students' aspirations and act upon them.

\section{References}

Caldwell, L., Darling N., Payne L. \& Dowdy B. (1999). "Why Are You Bored?": An Examination of Psychological and Social Control Causes of Boredom among Adolescents. Journal of Leisure Research, Vol. 31 (2), 103-121.

Csikszentmihalyi, M. (1990). Flow: The psychology of optimal experience. New York: Harper and Row.

Eccles, J., Midgely, C., Wigfield, A., Buchanan, C., Reuman, D., Flanagan, C. \& MacIver, D. (1993). Development during adolescence: The impact of stageenvironment fit on young adolescents' experiences in schools and in families. American Psychologist, 48, 90-101.

Farrell, E., Peguero, G., Lindsey, R. \& White, R. (1988). Giving voice to high school students: Pressure and boredom, ya know what I mean? American Educational Research Journal 4, 489-502.

Furtwengler, W.J. (1991). Reducing student misbehavior through student involvement in school restructuring processes. Wichita, KS: Wichita State University.

Holloway S. L. and Valentine G. (2003). Cyberkids: Children in the Information Age. Education and Information Technologies, 8 (4), 383-386.

Iso-Ahola, S. E. \& Weissinger, E. (1987). Leisure and boredom. Journal of Social and Clinical Psychology, 5(3), 356-364.

Johnson, J.H. (1991). Student voice: Motivating students through empowerment [Special issue]. OSSC Bulletin, 35(2). (ERIC Reproduction Service No. ED 337 875).

Kenway, J. \& Bullen, E. (2001). Consuming children (Buckingham, Open University Press).

Kushman, J.W. (1997). Look who's talking now: Student views of learning in restructuring schools. Portland, OR: Northwest Regional Educational Laboratory.

Larson, R. W. \& Richards, M. H. (1991). Boredom in the middle school years: Blaming schools versus blaming students. American Journal of Education, 99(4), 418-443.

MacBeath, J., Demetriou, H., Rudduck, J. \& Myers, K. (2003) Consulting students: a toolkit for teachers (Cambridge, Pearson Publishing).

Merriman, N. (2004) Introduction: diversity and dissonance in public archaeology, in:N. Merriman (Ed.) Public archaeology (London, Routledge).

Rudduck, J. \& Flutter, J. (2004) How to improve your school: giving pupils a voice (London, Continuum).

Weissinger, E., Caldwell, L. L. \& Bandalos, D. L. (1992). Relation between intrinsic motivation and boredom in leisure time. Leisure Sciences, 14, 317-325.

Wood, E. (2003). The power of pupils' perspectives in evidence-based practice: the case of gender and under-achievement, Research Papers in Education, 18(4), 365-383.

Yazzie-Mintz, E. (2007). Students are bored, many skip school, lack adult support. Center for Evaluation and Education Policy: Indiana University. 